\title{
Bispecific Antibody 4G7xH22
}

National Cancer Institute

\section{Source}

National Cancer Institute. Bispecific Antibody 4G7xH22. NCI Thesaurus. Code C2624.

A bispecific antibody containing a 4G7 hybridoma secreting IgG1 antibody specific for B-

lymphocytes and a monoclonal antibody targeting Fc gamma RI-expressing cells. 